Acta Hispanica (2019) 24: 49-73

\title{
LA VARIACIÓN DIALECTAL DE LOS VOCATIVOS EN LOS PAÍSES DE HABLA HISPANA
}

\author{
LILI TAKÁCS
}

Universidad Eötvös Loránd, Budapest

\begin{abstract}
Resumen: Este estudio se centra en la variación dialectal de los vocativos de cuatro países: España, México, Colombia y Venezuela. La finalidad de la investigación es profundizar en el tema de los vocativos dialectales y evitar malentendidos entre los hispanohablantes, así como sensibilizar a los estudiantes de ELE sobre un lenguaje más coloquial y nativo.

Primero estudiamos las características de los vocativos según los distintos niveles lingüísticos y después presentamos nuestro corpus, que consta de 400 intervenciones. A partir del corpus formulamos dos hipótesis: (1) existen vocativos pertenecientes a una sola variedad que no necesariamente son reconocibles para los hablantes de otros países; (2) las mismas palabras en función de vocativo presentan diferencias en cuanto a su significado, dependiendo de la variedad. Para justificarlas o rebatirlas diseñamos una encuesta de 6 preguntas, que fue rellenada por 140 personas, y presentamos los resultados obtenidos.
\end{abstract}

Palabras clave: dialectología, vocativo, apelativo, España, Latinoamérica

Abstract: The present study focuses on the dialectal variation of the vocatives of four countries: Spain, Mexico, Columbia and Venezuela. The aim of the research is to gain a deeper perspective of dialectal vocatives and to avoid misunderstandings between Spanish speaking people and also make students familiar with a more colloquial and native speaking.

After studying the characteristics of vocatives according to the different linguistic levels, a corpus of 400 examples is presented. Based on the corpus, two hypotheses were formulated: (1) there are vocatives that belong to only one variety and are not necessarily recognizable for speakers of other Spanish-speaking varieties; (2) the same words as vocatives show differences regarding their meaning depending on their variety. In order to justify or refute the hypotheses, a questionnaire of 6 questions was made that later was filled out by 140 informants. The rest of the study presents the results obtained in the research.

Keywords: Dialectology, Vocative, Apellative, Spain, Latin America

\section{Introducción}

El presente estudio se realizó con el fin de profundizar en el tema de los vocativos dialectales del español. Ante todo, es preciso definir el término vocativo: de acuerdo con la Real Academia Española (1999), este elemento es el nombre de la persona o cosa personificada a quien se le dirige la palabra y se sitúa en la periferia de la oración, separado por comas. Su función principal es mantener abierto el canal de comunicación, por lo tanto, son representantes de la comunicación fática del lenguaje (Domonkosi, 2002:49). Durante el estudio vocativo y apelativo aparecerán como sinónimos. 
La variación dialectal de los vocativos en los países de habla hispana

La idea de este tema ha surgido porque con el tiempo algunos vocativos han perdido su significado original y se han transformado independientemente. Este proceso ha causado que algunos apelativos en una variedad tengan un sentido aceptable para la sociedad, mientras que en otra causen provocación. El hecho de que uno no sea consciente del significado de una palabra en una variedad diferente de la suya puede generar situaciones bastante desagradables. Así que, por un lado, nuestra intención es presentar estos vocativos y examinar la diferencia en su uso, y, por otro, encontrar vocativos dialectales y estudiar su reconocimiento por los hablantes de otras variedades.

En esta ocasión nos centramos en los vocativos de cuatro países: España, México, Colombia y Venezuela. En la división dialectal no hemos optado por ninguna de las divisiones existentes, ni hemos tenido en cuenta los rasgos fonológicos, morfosintácticos y léxicos, simplemente hablamos de variedades según las fronteras oficiales de México, Colombia, Venezuela y España. Basándonos en nuestro corpus, que en total contiene 493 vocativos, creamos una encuesta en la que formulamos 6 preguntas a nuestros informantes (140 en total, 35 de cada país), con las que pretendemos obtener respuestas para justificar o rebatir dos hipótesis:

(1) existen vocativos pertenecientes a una sola variedad que no necesariamente son reconocibles para los hablantes de otros países;

(2) las mismas palabras en función de vocativo presentan diferencias en cuanto a su significado, dependiendo de la variedad.

A continuación, estudiamos las características de los vocativos según los niveles lingüísticos. En la parte restante del estudio presentamos nuestro corpus, la encuesta y los resultados.

\section{Caracterización de los vocativos según los niveles lingüísticos}

En este capítulo, tras definir el concepto, vamos a recopilar las características básicas del vocativo en los distintos niveles lingüísticos. Los ejemplos que aparecen son propios de nuestro corpus y sus códigos indican la fuente de donde proceden. Las fuentes se encuentran al final del estudio.

La Real Academia Española (1999:407) define el vocativo como el nombre de la persona o cosa personificada a quien se le dirige la palabra, y que está situado en la periferia de la oración. Según Baditzné y Takács (2018:23), si partimos del modelo tradicional de Jakobson sobre las funciones del lenguaje, podemos constatar que una de sus funciones básicas es la función conativa o apelativa (Jakobson 1968:347-360, apud Scholz Zavaleta 1997:367-371 y Boyer 2013:9-10), que sirve para que el hablante influya en la conducta de su interlocutor. De acuerdo con Bühler (1985, apud Bosque y Demonte 
2000:4037), el vocativo se define como el uso del nombre para apelar al oyente, uso que corresponde a la función apelativa del lenguaje.

Respecto a sus rasgos fonológicos, tal como se expone en Baditzné y Takács (2018:24), Alcina y Blecua (1975, apud Manuel Seco, 1989:86), constatan que los vocativos se distinguen por la presencia de un suprasegmento tonal característico que los separa, juntamente con pausas marcadas, del resto de la comunicación. Por lo tanto, quedan al margen de la oración y con una entonación independiente.

En cuanto a las características morfosintácticas, podemos constatar que el vocativo en general no lleva artículo. Su posición más frecuente en el habla coloquial es la colocación inicial en la oración, lo que sirve para atraer la atención del interlocutor: doctora, tengo un problema muy serio (MEX-1). En medio o al final de la oración es casi siempre enfático; su papel se suele limitar a reforzar la expresión o a suavizarla según los matices que la entonación refleje; muchas gracias, vecino, muchas gracias, ¿oyó? (COL-3) (Real Academia Española, 1999:407; 447).

En lo que concierne a la semántica de los vocativos, según la enumeración de Bosque y Demonte, se emplean las siguientes clases de nombres en función de vocativos: nombres propios (tanto su forma normal como formas diminutivas o hipocorísticas, como Chente); patronímicos (Jiménez); gentilicios (mexicano); nombres de parentesco (mama); nombres que denotan edad (joven); apodos (Jota); nombres que connotan trato íntimo (compadre); títulos (doctor); nombres de profesión (mesero) y términos "honoríficos" según la terminología de Brown y Levinson, apud Bosque y Demonte (4041), como señor, don, doña.

Para indicar cariño, algunos adjetivos, como querido o adorado, y algunos nombres comunes, como cariño o corazón, también se emplean como vocativos. La elección de estos vocativos puede resultar ofensiva y puede violar las normas de cortesía si se emplean hacia un interlocutor desconocido, especialmente si una mujer los recibe por parte de un hombre (Hasbún, 2003:202).

Algunos vocativos han pasado por una desemantización total o parcial. Por ejemplo, el vocativo hombre ya no se refiere solo a hombres, podemos dirigirnos a mujeres también con este apelativo, pero en este caso ya no se trata de un vocativo real, sino más bien una interjección con connotaciones de sorpresa y rechazo (Baditzné, 2015:135)

Pasando a la pragmática, como mencionan Bosque y Demonte (2000), algunos usos del vocativo se sitúan en la categoría de la cortesía. Cuando el hablante y el oyente se conocen, con el empleo del nombre propio al dirigirse uno a otro, se puede indicar cierta convencionalidad en el trato, lo que se denomina cortesía formal, mientras la falta 
La variación dialectal de los vocativos en los países de habla hispana

del nombre más bien es una actitud informal. Sin embargo, si nos basamos en nuestro corpus, esta teoría podría ser desmentida, porque en nuestros ejemplos, aunque contengan nombres propios, no detectamos ninguna formalidad: Hombre, Rafa, tío, ¿dónde estabas? (ESP-4).

\section{Corpus, metodología e hipótesis}

En esta sección presentamos la metodología que hemos utilizado para la recopilación de los ejemplos en los que se basa la parte restante del estudio, daremos detalles sobre nuestro corpus, mencionaremos la finalidad de nuestra encuesta y las hipótesis del propio estudio.

Esta investigación tiene como fin presentar los vocativos más populares de cuatro países: Colombia, España, México y Venezuela. Para la consecución de tal objetivo, hemos creado un corpus que consta de 400 ejemplos (enunciados, intervenciones o fragmentos de diálogos, que en total contiene 493 vocativos); 100 de cada país. Los enunciados fueron sacados de nueve telenovelas, siete películas, cuatro vídeos de YouTube, una serie y una página de Facebook.

Hemos formulado dos hipótesis para nuestra investigación:

(1) existen vocativos pertenecientes a una sola variedad que no necesariamente son reconocibles para los hablantes de otros países;

(2) las mismas palabras en función de vocativo presentan diferencias en cuanto a su significado, dependiendo de la variedad.

Para reforzar o refutar nuestras hipótesis, basándonos en nuestro corpus, creamos una encuesta que consta de 6 preguntas (sin contar las preguntas relacionadas con los datos personales). La finalidad de la encuesta era ampliar nuestros conocimientos en cuanto al uso de los vocativos encontrados y ver el reconocimiento y la popularidad de tales elementos en diferentes variedades. En la sección 4.1. presentaremos detalladamente las preguntas, los informantes, los resultados y las conclusiones de la encuesta.

La siguiente parte se dividirá en cuatro subcapítulos; cada uno presentando el corpus de un país estudiado, tratando etimológicamente los vocativos que más adelante se examinarán en la encuesta. Cada vocativo se ilustrará con un ejemplo propio, procedente de nuestro corpus.

\subsection{El corpus colombiano}

En los 100 ejemplos colombianos recopilados hemos encontrado en total 128 vocativos, entre ellos 40 diferentes. La mayoría no es propia de la variedad colombiana, 
pero sí detectamos la presencia de algunos vocativos que solo o mayoritariamente se encuentran en el habla colombiana como chino; huevón; nea; parce/parcero; pelado. En el próximo capítulo examinamos el significado y la etimología de las voces mencionadas.

\subsubsection{Chino}

De acuerdo con Flores (1963:289), su significado es "niño/a; chico/a". Partiendo de la idea de Carricaburo (2015:70), su etimología podría ser explicada con que los apodos familiares en la mayoría de los casos consisten en expresar características físicas del bebé que llaman la atención de sus padres, como es el caso de chino/a, que se emplea para al recién nacido que presenta los ojos rasgados y oblicuos, pero también puede señalar procedencia étnica o racial, sin un matiz peyorativo (71):

Se la van a dar, chino (COL-3).

\subsubsection{Güevón}

La palabra huevón se obtiene por sufijación aumentativa del vocablo vulgar hueva ('testículo') < huevo < ova, plural de ovum ('huevo') (Corominas, 1987:327).

Mientras en México güevón/huevón significa 'persona perezosa' (Haensch, 2002:45), tanto en Chile (Rojas, 2012:153), como en Colombia funciona como insulto, sinónimo de 'tonto', asociándose a la torpeza o poca inteligencia de una persona. En algunos casos se da sin su valor peyorativo y la connotación negativa se atenúa, debido a la relación simétrica entre los hablantes (Castellano, 2008:22, apud Castrillón, 2015:51). También es posible encontrar sus variantes en otras clases gramaticales, como huevada (sustantivo), ahuevonado (adjetivo) (Sáez-Godoy, 1983; Portocarrero, 1999 apud Moberg, 2015:1):

Uy, güevón, debería existir pico y placa para personas (COL-5).

\subsubsection{Nea}

De acuerdo con García Zapata (2014:47), procede de la forma 'gonorrea', proveniente del habla coloquial de Medellín. Según el Diccionario Clave, gonorrea procede del griego gonórroia ('flujo seminal'), y este de gónus ('esperma'). Quizá es el término más ofensivo actualmente en esa área, ya que difama al insultado al nombrarlo con una enfermedad venérea considerada despreciable. Este insulto surgido de los estratos bajos de la sociedad se ha difundido rápidamente en el registro coloquial, tanto en hombres como en mujeres:

Nea, pero a mí me gusta empezar mal la materia porque así me siento con más adrenalina (COL-5). 
La variación dialectal de los vocativos en los países de habla hispana

\subsubsection{Parce/Parcero}

Parcero viene de la palabra 'aparcero' (García Padrón, 2004:476), que es una evolución de la palabra latina PARTitarius ('partícipe') (Diccionario Clave, 23-09-2019). Parce es un acortamiento del mismo (procedente del lenguaje argótico paisa), con el significado 'amigo' o 'compañero' (Castañeda Naranjo y Henao, 2012:56). Según Richard (2006:335), es un tratamiento que se da entre compañeros de trabajo o socios que comparten los mismos peligros, los mismos problemas:

Parce, usted se enamoró de él en tres días (COL-5).

\subsubsection{Pelado/a}

De acuerdo con Corominas (1987:448), pelado deriva de pelar, que viene del latín PILARE ('sacar el pelo'). Sus componentes léxicos son PILus ('pelo') y el sufijo -ar (desinencia verbal). En el estudio de Flores (1963:289) se encuentra este vocativo con el significado de "chico/a; muchacho/a, un pelao, una pelada". Rodríguez (2013:154) lo menciona como elemento de la lengua coloquial y de uso muy frecuente en el español colombiano. Castrillón (2015:49) entre los tratamientos amistosos menciona pelado o peladito como forma de tratar a los niños y a los jóvenes colombianos, aunque, según Richard (2006:345), no solo puede ser cariñoso sino despectivo también. Fuera de Colombia, pelao o pelaito es usado también tanto en Venezuela como Panamá para apelar a los niños (Carricaburo, 2015:73-80):

¿Entonces qué, pelado? ¿Todo bien o qué? (COL-3).

\subsection{El corpus español}

En los 100 ejemplos hemos encontrado en total 119 vocativos, entre ellos, 35 diferentes. Algunos de los vocativos mencionados son propios de la variedad española, como: capullo; chaval; gilipollas; tio/a, cuyo significado y etimología se examinará en el capítulo siguiente.

\subsubsection{Capullo}

Del latín cucullus ('capucha') (Diccionario Clave). Su significado original, según el Diccionario de la Real Academia Española, es ‘envoltura del gusano' o ‘botón de las flores', pero también es común su uso como palabra vulgar con el sentido de 'persona torpe', 'de malas intenciones', 'estúpido', 'desgraciado', 'novato' (Carbonero, 2004:71, León, 1984:47). Se da frecuentemente en España en círculos de jóvenes o en grupos más o menos cerrados (Carricaburo, 2015:78-79), con el sentido ofensivo (León, 1984:47):

A ver lo valiente que eres, capulla (ESP-1). 


\subsubsection{Chaval}

Es de frecuente uso en España entre jóvenes (Carricaburo, 2015:79), cuyo origen viene del caló (lengua hablada por los gitanos españoles) čavále, vocativo masculino plural de čavó, 'hijo', 'muchacho', que fue documentada por primera vez en 1870 como voz gitana (Velázquez, 1956:229):

Son los mejores chupitos del mundo, chaval (ESP-5).

\subsubsection{Gilipollas}

Según el Diccionario de la Real Academia Española, esta palabra es una vulgarización del adjetivo gilí, término que designa a una persona tonta, lela, estúpida (León, 1984:78) y que procede del vocablo caló jilí, cuyo significado es 'inocente' o 'cándido'. Su uso es frecuente en España entre jóvenes (Carricaburo, 2015:79):

Y tú ¿quieres que te pegue un guantazo, gilipollas? (ESP-2).

\subsubsection{Tío/a}

Del latín tardío THǏUs, TH1̌A, y estos del griego thêios ('tío'), théia ('tía') (Corominas, 1987:568; Diccionario Glosbe, 23-09-2019).

De acuerdo con Carricaburo (2015:74; 78-79), algunos lazos familiares van más allá de su significado original, como es el caso de tío/a, que actualmente es un vocativo de la Península que se da entre amigos y compañeros, mayoritariamente entre adolescentes y jóvenes, quienes a veces incluso se dirigen con este vocativo al padre para marcar el compañerismo. Fuera del uso del vocativo, también con el significado de "tipo", se oyen expresiones como “¿quién es el tío ese?”, “qqué bien estuvo el tío ese!”, o en otros casos con significado injurioso como “iqué tío ladrón!” o “¡vaya tío!” (Carricaburo, 2015:74):

¿En serio, tio? Pero, tío, en el día de la fiesta en casa de Tania me dijiste que te liaste con ella (ESP-5).

\section{3. $\mathrm{E} 1$ corpus mexicano}

En los 100 ejemplos, en total detectamos la presencia de 123 vocativos, entre ellos, 47 diferentes.

Los vocativos encontrados se pueden dar en otras áreas de habla hispana también, pero vale la pena destacar algunos que son particulares en la variedad mexicana, como carnal; güero; güey. En el próximo capítulo haremos conocer el significado y la etimología de los apelativos mencionados. 
La variación dialectal de los vocativos en los países de habla hispana

\subsubsection{Carnal}

Carnal ('hermano de sangre') deriva del vocablo carne, del latín CARO ('carne') (Corominas- Pascual, 1980:878).

Manzini (2017:32) lo menciona con el significado de 'hermano' o 'amigo', de uso apelativo y narrativo en los barrios pobres (Carricaburo, 2015:80). Bürki (2014:417) considera que el término carnal es representante del habla de un sustrato social bajo, los que se denominan como nacos ('de mal gusto', 'ignorante que carece de educación') (402): Pa' que no se te olvide, compa, soy sangre de su sangre, carnal (MEX-5).

\subsubsection{Güero}

De huero, forma procedente del verbo hispánico GŌRĀRE ('incubar'), de origen céltico (Corominas, 1987:326). El autor explica que huero ('huevo que por no estar fecundado o por cualquier otra causa se pierde en la incubación) pasó a 'cosa malograda o sin sustancia en general', después a 'hombre enfermizo' y de ahí a 'hombre de tez clara'. De acuerdo con Ávila (2011:164), Manzini (2017:33) y Parodi (2003:30), es un adjetivo con el significado de 'rubio', de 'cabello raro', una forma cariñosa utilizada en México (Carricaburo, 2015:72). Aunque mayoritariamente se emplea para personas de tez clara y cabello rubio, cualquier otro que no sea negro puede recibir este vocativo, utilizado, sobre todo, por los vendedores que apelan a la creencia (sub)consciente de que ser güero es por definición ser atractivo (D'Amore Wilkinson, 2013:210):

Güerita, ahora si se va a poner buenísima la fiesta, corąón (MEX-7).

\subsubsection{Güey}

Coloquialmente escrito como 'wey', viene de buey < buee < BǒE < BǒvEM (Corominas, 1987:110), significa, según el Diccionario del Español Usual en México (1996, apud Mugford Fowler y otros, 2013:211), 'tonto', 'persona desconocida' y 'despreciada', pero especialmente sirve para asegurar la comunicación fática entre los jóvenes. Como menciona Fowler (211), el uso de la palabra güey se puede encontrar en toda la sociedad en situaciones informales, e incluso en formales:

Güey, ya sé, o sea, yo con mi piel tan tersa y delicada, güey, hace daño mil (MEX-9).

\subsection{E1 corpus venezolano}

En los 100 ejemplos en total se encuentran 123 vocativos, entre ellos, 32 diferentes. La mayoría de los vocativos encontrados se pueden dar en otras variedades también, pero algunos proceden del habla venezolana, o son sumamente populares, como chamo; pana; vale; y aunque no lo detectamos en nuestro corpus, marico/a. En el próximo capítulo se presentará el significado y la etimología de las voces mencionadas. 


\section{Lili Takács}

\subsubsection{Chamo}

La etimología de chamo todavía no está bien definida porque no se encuentra información de fuentes fiables, aunque en las páginas web se pueden encontrar algunas teorías. Una de estas es que este vocablo viene del inglés chum ('camarada', 'compañero').

Otra aproximación se remonta a los años 40, cuando los inmigrantes portugueses se referían con la palabra 'chamada' ('llamada') a alguien desconocido, por lo que el uso se quedó en el español venezolano y la palabra se transformó en 'chamo’.1 El significado, según el diccionario de Wordreference, es 'niño o adolescente', mientras Llorente Pinto (2000:241) lo menciona como equivalente de 'amigo'. Esta palabra es de frecuente uso en la juventud venezolana, se utiliza para referirse tanto a un interlocutor como para hablar de una tercera persona (Carricaburo, 2015:80; Lo Ponte Pérez, 2016:101): Tranquilo, chamo, mire, me meti en el pub esta mañana (VZL-3).

\subsubsection{Pana}

Pana originalmente es una voz quechua con el significado de 'hermana de varón' (Cerrón- Palomino, 2016:19). De acuerdo con Del Valle de Villalba (2013:142), pana en Venezuela es 'compañero', 'amigo', pero uno que sea allegado. No tiene distinción de sexo, es decir, la forma femenina y masculina concuerda. Su uso es frecuente tanto entre amigos como entre jóvenes que no se conocen. La palabra pana ha cambiado su significado a través de los años, por lo que ya no solo desempeña la función de sustantivo, sino que también tiene la función de adjetivo descriptivo, utilizado como sinónimo de 'simpático' o ‘agradable' (Carricaburo, 2015:73-80, Lo Ponte Pérez, 2016:108):

Mire, pana, disculpe que me meta, pero tú eres el unico quien no tiene la verdad (VZL-5).

\subsubsection{Marico/a}

Marica viene del nombre femenino María (Diccionario Clave, 23-09-2019).

Aunque en nuestro corpus no se haya detectado, consideramos importante su mención, ya que, basándonos en otros corpus, su uso es frecuente en Venezuela y también aparecerá en nuestra encuesta. De acuerdo con Gutiérrez-Rivas (2016:5), el término marico era usado tradicionalmente para designar despectivamente a los hombres homosexuales. En el diccionario de venezolanismos (apud Gutiérrez-Rivas, 2016:5), Tejera (1983:174) define marico de la siguiente forma: "Masculino. Vulgar. Región central, los llanos y Andes. Hombre afeminado u homosexual. Se emplea también solo como insulto". La forma femenina también existe: "Femenino. Insulto. Vulgar. Región

\footnotetext{
${ }^{1}$ Información obtenida de la página web rumbacaracas.com (10-10-2018).
} 
central, los llanos y Andes. Se les dice a las mujeres" (1983:174). Sin embargo, ya empiezan a encontrarse en Internet una serie de sitios web que reseñan el uso de la palabra como un coloquialismo que es empleado entre amigos hombres (y, ocasionalmente, entre mujeres con la variante femenina marica) (Gutiérrez-Rivas, 2016:5). Como menciona la misma autora en su estudio (12) y Lo Ponte Pérez (2016:107), marico/a funciona como una muletilla y puede sustituir vocativos del habla típica venezolana, como es el caso de chamo, así como para tratar con una amiga específica, o solo con amigos.

\subsubsection{Vale}

Derivación de valer, del latín VALĒRE ('ser fuerte, vigoroso, potente', 'estar sano') (Corominas, 1994:596).

A diferencia de las demás palabras, este vocativo es una forma conjugada de un verbo, por lo que a primera vista puede resultar extraño a los que no conocen su significado en esta variedad. Este apelativo es común en Venezuela (Carricaburo, 2015:80) con el significado de 'amigo' u 'hola' (Lipski, 2014:385), mientras que, según Richard (2006:467), en la República Dominicana su significado es 'campesino', y también existe la forma "bale":

Vale, morena, vale, ¿cómo vas a preguntar eso, vale? (VZL-5).

\section{Encuesta}

Como ya se ha mencionado, para la realización de la encuesta nos basamos en nuestro corpus, eligiendo los vocativos más utilizados. Hemos formulado 6 preguntas con el fin de acercarnos al uso de tales vocativos y ver hasta qué punto son reconocibles para hablantes de otras variedades. También nos habría gustado ver la aceptación social de ciertos elementos, ya que puede variar el significado según la variedad.

En esta sección, primero presentaremos los datos de nuestros informantes, y después daremos a conocer el resultado de algunas preguntas. Todas no pueden ser presentadas en este estudio, mas servirán como base en nuestras futuras investigaciones.

\subsection{Datos de los informantes}

El cuestionario ha sido rellenado por 140 hablantes nativos del español; 35 colombianos, 35 españoles, 35 mexicanos y 35 venezolanos. Un número significativo de ellos ha vivido en otros países también, como Hungría, España o Inglaterra.

En cuanto al sexo, las mujeres ocupan el $60,7 \%$ de la encuesta, mientras que los hombres solo el 39,3\%. 


\section{Lili Takács}

La edad de nuestros informantes varía entre los 15 y 70 años. Tal como se puede observar en las figuras 2-3, destaca la presencia de veinteañeros, pero también se dan en un gran porcentaje los treintañeros.

\section{Edad}

140 respuestas

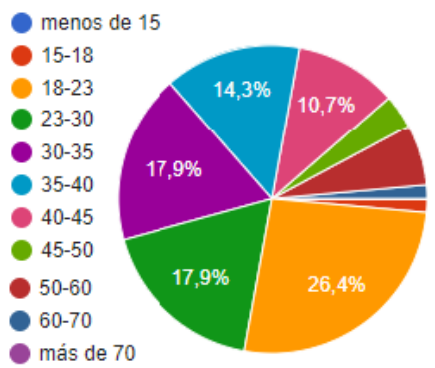

\section{Sexo}
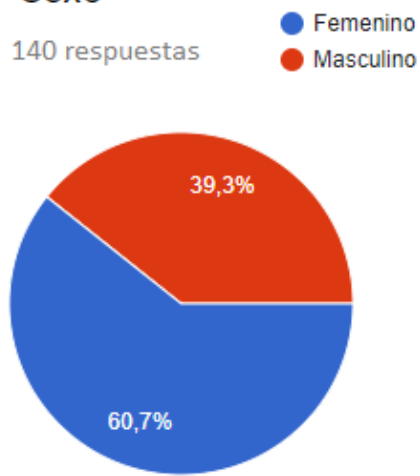

Figuras 1-2. Edad y sexo de los informantes

En lo que concierne al título académico más alto, más de la mitad de los encuestados ha terminado la educación superior, el $27 \%$ la está cursando y el $9 \%$ está haciendo el doctorado o ya lo ha terminado, por lo que se puede observar que la gran mayoría pertenece a un grupo social culto.

\section{Nacionalidad}

140 respuestas
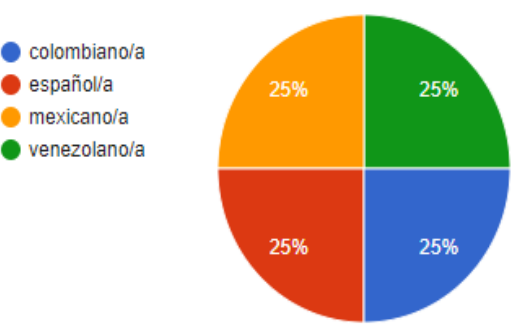

\section{Título académico más alto}

\section{0 respuestas}

Primaria (en curso)

Primaria (terminado)

Secundaria (en curso)

Secundaria (terminado)

Bachillerato/Preparatoria (en curso)

- Bachillerato/Preparatoria (terminado)

- Educación superior (en curso)

Educación superior (terminado)

Doctorado (en curso)

Doctorado (terminado)

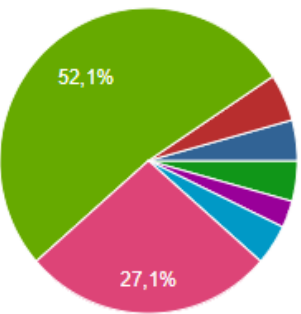

Figuras 3-4. Nacionalidad y el título académico más alto de los informantes. 
La variación dialectal de los vocativos en los países de habla hispana

\subsection{Hipótesis I - resultados de los vocativos dialectales}

Como ya se ha dicho, nuestra primera hipótesis es que algunos vocativos son propios de una variedad, lo que se refleja en la frecuencia de su uso y no necesariamente son reconocibles para los extranjeros.

Para crear las preguntas, hemos elegido 8 vocativos en total: parcero y pelado de Colombia; gilipollas y tío/tía de España; carnal y güey de México; chamo y pana de Venezuela. El propósito con las preguntas era ver la frecuencia de estas voces y que según la opinión de los hablantes a quién se puede apelar con estos elementos y si los hablantes de una variedad son capaces de reconocer vocativos de otras variedades.

La primera pregunta fue “¿Qué le parece el vocativo...?” y puestos todos los vocativos mencionados, los informantes tenían que elegir de las siguientes opciones: suelo usarlo; conozco el significado, pero no lo uso; me parece extranjerismo; no sé; otro.

\begin{tabular}{|c|c|c|c|c|c|}
\hline \multicolumn{7}{|c|}{ ESPAÑ } \\
\hline & suelo usarlo & $\begin{array}{c}\text { conozco el significado } \\
\text { pero no lo uso }\end{array}$ & $\begin{array}{c}\text { me parece } \\
\text { extranjerismo }\end{array}$ & no sé & otro \\
\hline parcero & 0 & 5 & 9 & 20 & 0 \\
\hline gilipollas & 24 & 10 & 0 & 1 & 0 \\
\hline chamo & 0 & 6 & 13 & 16 & 0 \\
\hline güey & 0 & 19 & 9 & 7 & 0 \\
\hline pelado & 2 & 11 & 5 & 17 & 0 \\
\hline tio/tia & 32 & 3 & 0 & 0 & 0 \\
\hline pana & 0 & 15 & 5 & 15 & 0 \\
\hline carnal & 0 & 8 & 6 & 20 & 1 \\
\hline
\end{tabular}

Tabla 1. La respuesta de los españoles para la pregunta “¿Qué le parece el vocativo....?”.

En cuanto a los españoles, casi todos los informantes usan el vocativo tío/ tía, mientras que solamente 24 personas de las 35 usan gilipollas. Quizás un factor que puede influir sea la edad, ya que gilipollas suele ser más frecuente en el habla juvenil. Por otro lado, es más vulgar que los demás vocativos analizados y es posible que para algunos parezca malsonante por lo que intentan evitar su uso.

60 | Acta Hispanica (2019) 24 


\begin{tabular}{|c|c|c|c|c|c|}
\hline \multicolumn{7}{|c|}{ COLOMBLA } \\
\hline & suelo usarlo & $\begin{array}{c}\text { conozco el significado } \\
\text { pero no lo uso }\end{array}$ & $\begin{array}{c}\text { me parece } \\
\text { extranjerismo }\end{array}$ & no sé & otro \\
\hline parcero & 21 & 14 & 0 & 0 & 0 \\
\hline gilipollas & 1 & 21 & 10 & 1 & 2 \\
\hline chamo & 3 & 21 & 7 & 2 & 2 \\
\hline güey & 6 & 17 & 9 & 1 & 2 \\
\hline pelado & 18 & 14 & 1 & 1 & 1 \\
\hline tio/tia & 3 & 23 & 7 & 0 & 2 \\
\hline pana & 9 & 21 & 5 & 0 & 0 \\
\hline carnal & 0 & 25 & 8 & 0 & 2 \\
\hline
\end{tabular}

Tabla 2. La respuesta de los colombianos para la pregunta “¿Qué le parece el vocativo....?”.

En las respuestas de los colombianos podemos notar que menos personas usan los elementos de su propia variedad que en el caso de los españoles, lo que podría ser explicado con que parcero y pelado no de todas maneras pertenecen al mismo nivel social. También podemos observar que 9 personas de 35 usan el vocativo pana (según nuestra división, perteneciente a la variedad venezolana), lo que puede deberse a que según algunas divisiones hay partes de Colombia y Venezuela que pertenecen a la misma área dialectal (Lipski, 2014:18), por lo que es posible que compartan algunos vocablos.

\begin{tabular}{|c|c|c|c|c|c|}
\hline \multicolumn{7}{|c|}{ MÉXICO } \\
\hline & suelo usarlo & $\begin{array}{c}\text { conozco el significado } \\
\text { pero no lo uso }\end{array}$ & $\begin{array}{c}\text { me parece } \\
\text { extranjerismo }\end{array}$ & no sé & otro \\
\hline parcero & 0 & 13 & 15 & 7 & 0 \\
\hline gilipollas & 1 & 16 & 14 & 4 & 0 \\
\hline chamo & 2 & 10 & 13 & 9 & 2 \\
\hline güey & 28 & 5 & 1 & 1 & 0 \\
\hline pelado & 12 & 17 & 15 & 5 & 0 \\
\hline tio/tia & 4 & 15 & 12 & 8 & 0 \\
\hline pana & 2 & 13 & 2 & 2 & 1 \\
\hline carnal & 17 & 13 & & 1 & 0 \\
\hline
\end{tabular}

Tabla 3. La respuesta de los mexicanos para la pregunta “¿Qué le parece el vocativo...?”.

En lo que concierne a los mexicanos, 28 de 35 personas utilizan el vocativo güey, mientras que solo 17 informantes han marcado esta opción sobre carnal, lo que supuestamente se debe a que esta palabra quizás no goce de gran popularidad entre un sustrato de nivel más educado.

Cabe destacar que pelado (que suponíamos ser propio de la variedad colombiana) parece ser de frecuente uso en México también. El uso de los demás elementos puede ser explicado con que quizá el informante haya vivido en otros países y así adoptara ciertos vocablos nuevos. 
La variación dialectal de los vocativos en los países de habla hispana

\begin{tabular}{|c|c|c|c|c|c|}
\hline \multicolumn{7}{|c|}{ VENEZUELA } \\
\hline & suelo usarlo & $\begin{array}{c}\text { conozco el significado } \\
\text { pero no lo uso }\end{array}$ & $\begin{array}{c}\text { me parece } \\
\text { extranjerismo }\end{array}$ & no sé & otro \\
\hline parcero & 2 & 23 & 9 & 1 & 0 \\
\hline gilipollas & 3 & 21 & 10 & 2 & 0 \\
\hline chamo & 32 & 2 & 1 & 0 & 0 \\
\hline güey & 2 & 21 & 11 & 1 & 0 \\
\hline pelado & 3 & 19 & 11 & 2 & 0 \\
\hline tio/tia & 4 & 21 & 10 & 0 & 0 \\
\hline pana & 33 & 1 & 1 & 0 & 0 \\
\hline carnal & 0 & 22 & 13 & 0 & 0 \\
\hline
\end{tabular}

Tabla 4. La respuesta de los venezolanos para la pregunta “¿Qué le parece el vocativo...?”.

Entre los cuatro países, los venezolanos son los que más utilizan los vocativos de su propia variedad, y también la mayoría conoce el significado de los elementos de los demás países.

En conclusión, podemos constatar que los vocativos dialectales no son usados por todos los hablantes de tal país, lo que puede ser debido a que ciertos elementos se pueden categorizar según la edad o el nivel intelectual del hablante, como en el caso de carnal, parcero o gilipollas.

En la siguiente pregunta nuestra intención fue ver en qué medida los hablantes eran capaces de reconocer las voces de diferentes países; así, dados los mismos 8 vocativos, tenían que decidir si pertenecían a la variedad mexicana; colombiana; venezolana; española; pero también podían responder con no sé u otro.

En lo que concierne a su reconocimiento, los hablantes de los países latinos conocen bastante bien los vocativos de otros países latinos y los términos españoles también, mientras que la mayoría de los españoles no conocía las voces latinoamericanas (excepto güey). Esto puede tener una posible explicación: el factor que pudo influir en las respuestas de los informantes latinos es que varios de los informantes en algún momento habían vivido en ciudades europeas, donde posiblemente estaban en contacto con españoles, por lo que conocen sus palabras.

Después de haber visto hasta qué punto son reconocibles estos ocho vocativos, también formulamos una pregunta donde los encuestados tenían que elegir si en ciertas relaciones podría o no ser adecuado el uso de los elementos mencionados. En esta respuesta se podían marcar más opciones. En la tabla solo aparecen las respuestas de los hablantes a cuya variedad pertenece el vocativo cuestionado. 


\begin{tabular}{|c|c|c|c|c|c|c|c|}
\hline \multicolumn{2}{|c|}{ Cree que podría ser adecuado el uso de...? } \\
\hline & $\begin{array}{c}\text { en una relación de } \\
\text { amigos }\end{array}$ & $\begin{array}{c}\text { entre } \\
\text { desconocidos }\end{array}$ & entre hermanos & entre una pareja & $\begin{array}{c}\text { en una relación } \\
\text { asimétrica: a } \\
\text { superiores }\end{array}$ & $\begin{array}{c}\text { en una relación } \\
\text { asimétrica: a } \\
\text { inferiores }\end{array}$ & no sé \\
\hline parcero & 35 & 6 & 6 & 1 & 0 & 1 & 0 \\
\hline gilipollas & 21 & 9 & 10 & 5 & 2 & 8 & 3 \\
\hline chamo & 33 & 21 & 16 & 8 & 3 & 11 & 0 \\
\hline güey & 32 & 12 & 15 & 4 & 1 & 8 & 0 \\
\hline pelado & 19 & 11 & 1 & 0 & 0 & 8 & 3 \\
\hline tio/tia & 32 & 8 & 13 & 6 & 1 & 3 & 1 \\
\hline pana & 34 & 19 & 14 & 7 & 4 & 8 & 0 \\
\hline carnal & 29 & 5 & 18 & 0 & 0 & 1 & 1 \\
\hline
\end{tabular}

Tabla 5. Respuestas para la pregunta “¿Cree que podría ser adecuado el uso de...?”

Tras analizar la tabla, podemos llegar a varias conclusiones. Parcero, güey, tío y carnal son los que más sirven para apelar al oyente en una relación de amigos. Los vocablos venezolanos, chamo y pana, van más allá del lazo de amistad y también son de frecuente uso entre desconocidos o hermanos. Entre una pareja y en relaciones asimétricas los elementos mencionados no gozan de gran popularidad, aunque para inferiores se emplean más que para superiores.

\subsection{Hipótesis II - resultados de los vocativos cuyo significado varía entre variedades}

En esta sección vamos a presentar los resultados que recibimos en nuestro cuestionario para corroborar o rebatir nuestra segunda hipótesis, que es la siguiente: las mismas palabras en función de vocativo presentan diferencias en cuanto a su significado, dependiendo de la variedad.

Primero, preguntamos sobre los vocativos amigo; colega, compadre; compañero y hermano y después nos centramos en elementos como mamacita/mamita y marico/marica y en la consideración social que tienen.

\subsubsection{Resultados de los vocativos de amistad}

Basándonos en nuestro corpus, hemos elegido los 5 vocativos que designan amistad y los examinaremos en esta sección. Nuestro objetivo fue ver que estos vocativos, que a primera vista parecen ser apelativos de confianza, en qué otras situaciones o relaciones podrían ser utilizados.

En esta pregunta tenían que elegir si con amigo; colega; compadre; compañero y hermano se dirigirían: a un amigo; a un desconocido; a un conocido, pero no amigo; a un familiar, o bien, optar por las opciones no lo usaría y otro. 
La variación dialectal de los vocativos en los países de habla hispana

\begin{tabular}{|c|c|c|c|c|c|c|}
\hline \multicolumn{7}{|c|}{ AMIGO } \\
\hline & a su amigo & a un desconocido & $\begin{array}{c}\text { a un conocido } \\
\text { pero no amigo }\end{array}$ & $\begin{array}{c}\text { a un } \\
\text { familiar }\end{array}$ & no lo usaria & otro \\
\hline españoles & 35 & 1 & 2 & 4 & 0 & 0 \\
\hline colombianos & 30 & 7 & 7 & 1 & 0 & 0 \\
\hline mexicanos & 35 & 1 & 2 & 4 & 0 & 0 \\
\hline venezolanos & 29 & 11 & 11 & 3 & 0 & 3 \\
\hline
\end{tabular}

Tabla 6. Respuestas sobre el vocativo amigo

En cuanto a amigo, en la mayoría de los cuatro países resultó ser apelativo entre amigos de verdad, aunque en Venezuela y en Colombia una parte de los encuestados también se le dirigiría a un desconocido o a un conocido, pero no amigo, con este vocativo.

\begin{tabular}{|c|c|c|c|c|c|c|}
\hline \multicolumn{7}{|c|}{ COLEGA } \\
\hline & a su amigo & $\begin{array}{c}\text { a un } \\
\text { desconocido }\end{array}$ & $\begin{array}{c}\text { a un conocido } \\
\text { pero no amigo }\end{array}$ & a un familiar & no lo usaria & otro \\
\hline españoles & 24 & 2 & 12 & 2 & 4 & 2 \\
\hline colombianos & 8 & 5 & 13 & 0 & 6 & 6 \\
\hline mexicanos & 8 & 9 & 23 & 1 & 6 & 3 \\
\hline venezolanos & 12 & 12 & 16 & 1 & 6 & 7 \\
\hline
\end{tabular}

Tabla 7. Respuestas sobre el vocativo colega

Colega parece ser más popular entre amigos en España, mientras que en los países latinos, especialmente en México, la gente se dirigiría con este vocativo a un conocido, pero no amigo.

\begin{tabular}{|c|c|c|c|c|c|c|}
\hline \multicolumn{7}{|c|}{ COMPADRE } \\
\hline & a su amigo & $\begin{array}{c}\text { a un } \\
\text { desconocido }\end{array}$ & $\begin{array}{c}\text { a un conocido } \\
\text { pero no amigo }\end{array}$ & a un familiar & no lo usaria & otro \\
\hline españoles & 14 & 1 & 5 & 2 & 17 & 1 \\
\hline colombianos & 23 & 2 & 2 & 9 & 6 & 2 \\
\hline mexicanos & 21 & 2 & 4 & 9 & 7 & 4 \\
\hline venezolanos & 23 & 6 & 6 & 7 & 9 & 4 \\
\hline
\end{tabular}

Tabla 8. Respuestas sobre el vocativo compadre

La mitad de los españoles no usaría compadre, mientras la otra mitad apelaría a su amigo con esta palabra, como en el caso de los países latinos, donde la mayoría lo usaría para 
su amigo, y algunos venezolanos también para personas con las que no tienen ninguna o solo poca relación.

\begin{tabular}{|c|c|c|c|c|c|c|}
\hline \multicolumn{7}{|c|}{ COMPANERO } \\
\hline & a su amigo & $\begin{array}{c}\text { a un } \\
\text { desconocido }\end{array}$ & $\begin{array}{c}\text { a un conocido } \\
\text { pero no amigo }\end{array}$ & a un familiar & no lo usaria & otro \\
\hline españoles & 9 & 5 & 22 & 1 & 3 & 1 \\
\hline colombianos & 11 & 4 & 23 & 1 & 2 & 1 \\
\hline mexicanos & 7 & 11 & 24 & 1 & 3 & 3 \\
\hline venezolanos & 11 & 10 & 22 & 2 & 5 & 4 \\
\hline
\end{tabular}

Tabla 9. Respuestas sobre el vocativo compañero

Compañero parece ser un vocativo que es más frecuente entre conocidos, pero no amigos, y en México y en Venezuela incluso una parte lo utilizaría para totalmente desconocidos.

\begin{tabular}{|c|c|c|c|c|c|c|}
\hline \multicolumn{7}{|c|}{ HERMANO } \\
\hline & a su amigo & a un desconocido & $\begin{array}{c}\text { a un conocido } \\
\text { pero no amigo }\end{array}$ & $\begin{array}{c}\text { a un } \\
\text { familiar }\end{array}$ & no lo usaria & otro \\
\hline españoles & 18 & 0 & 1 & 23 & 4 & 0 \\
\hline colombianos & 27 & 3 & 4 & 21 & 2 & 0 \\
\hline mexicanos & 26 & 0 & 2 & 23 & 0 & 1 \\
\hline venezolanos & 27 & 7 & 8 & 18 & 3 & 4 \\
\hline
\end{tabular}

Tabla 10. Respuestas sobre el vocativo hermano

Como ha dicho Carricaburo (2015), algunos lazos familiares van más allá de su significado original, así, hermano es de uso popular entre amigos en los cuatro países mencionados. Una parte de los venezolanos también se dirigiría a desconocidos o conocidos, pero no amigos.

\subsubsection{Resultados de los vocativos provocativos}

En esta sección trataremos cómo reacciona la gente a vocativos (como mamacita/mamita y marico/marica;) que en unas variedades son aceptados y usados, mientras que en otras pueden resultar bastante provocativos o hasta ofensivos. 


\begin{tabular}{|c|c|c|c|c|}
\hline \multicolumn{5}{|c|}{ SI USTED ES HOMBRE ¿Qué opina del vocativo mamacita/mamita? } \\
\hline & $\begin{array}{c}\text { en mi dialecto se usa } \\
\text { para expresar cariño } \\
\text { hacia las mujeres }\end{array}$ & $\begin{array}{c}\text { lo uso cuando me gusta una } \\
\text { mujer }\end{array}$ & me parece ofensivo & otro \\
\hline MÉXICO & 3 & 4 & 9 & 2 \\
\hline COLOMBIA & 7 & 6 & 3 & 1 \\
\hline VENEZUELA & 5 & 2 & 5 & 5 \\
\hline ESPAÑA & 1 & 0 & 5 & 4 \\
\hline TOTAL & 16 & 12 & 22 & 12 \\
\hline
\end{tabular}

Tabla 11. La opinión de los hombres sobre el vocativo mamacita/ mamita

Primero, preguntamos a los hombres qué opinión tenían sobre la voz mamacita/mamita. De los resultados podemos llegar a la conclusión de que en la variedad española no se utiliza para expresar cariño hacia las mujeres, más bien, les pareció ofensivo a los hombres. Como suponíamos, para los colombianos es una voz que expresa cariño, pero también se puede expresar que a uno le gusta una mujer. A la mayoría de los mexicanos les parece ofensivo, pero algunos también lo usarían cuando les gusta una mujer.

En Venezuela la misma cantidad de personas eligió la opción "en mi dialecto se usa para expresar cariño hacia las mujeres", "lo uso cuando me gusta una mujer" y "otro", así que en este caso no se puede llegar a una conclusión consensual, sino que, más bien, la opinión parece dividida. 


\begin{tabular}{|c|c|c|c|c|}
\hline \multicolumn{5}{|c|}{ SI USTED ES MUJER ¿Qué opina del vocativo mamacita/mamita? } \\
\hline & $\begin{array}{c}\text { en mi dialecto se usa sin } \\
\text { ningún sentido ofensivo }\end{array}$ & $\begin{array}{c}\text { me parece ofensivo solo en el } \\
\text { caso de que me lo digan con } \\
\text { una entonación ofensiva }\end{array}$ & $\begin{array}{c}\text { siempre me parece } \\
\text { ofensivo }\end{array}$ & otro \\
\hline MÉXICO & 2 & 16 & 2 & 2 \\
\hline COLOMBIA & 7 & 12 & 2 & 0 \\
\hline VENEZUELA & 3 & 12 & 4 & 1 \\
\hline ESPAÑA & 9 & 11 & 1 & 4 \\
\hline TOTAL & 21 & 51 & 9 & 7 \\
\hline
\end{tabular}

Tabla 12. La opinión de las mujeres sobre el vocativo mamacita/ mamita

En cuanto a las mujeres, la mayoría de los cuatro países considera que mamacita/mamita es ofensivo solo si la entonación no es adecuada. Es interesante que las mujeres colombianas también hayan opinado lo mismo, aunque, partiendo de los resultados de los hombres, este vocativo se usa sin ningún sentido ofensivo en Colombia.

\begin{tabular}{|c|c|c|c|c|}
\hline \multicolumn{7}{|c|}{ QQué opina del vocativo marico/marica? } \\
\hline & $\begin{array}{c}\text { in mialecto se usa para } \\
\text { ennominar amigos o conocidos }\end{array}$ & $\begin{array}{c}\text { para mi significa homosexual y me } \\
\text { parece ofensivo }\end{array}$ & $\begin{array}{c}\text { como sé que en otros dialectos } \\
\text { significa amigo, no me ofende en } \\
\text { absoluto }\end{array}$ & otro \\
\hline MÉXICO & 1 & 23 & 8 & 11 \\
\hline COLOMBIA & 21 & 4 & 7 & 10 \\
\hline VENEZUELA & 23 & 3 & 4 & 9 \\
\hline ESPAÑA & 2 & 21 & 5 & 12 \\
\hline TOTAL & 47 & 51 & 24 & 18 \\
\hline
\end{tabular}

Tabla 13. Respuestas sobre el vocativo marico/marica

Después, preguntamos sobre marico/marica, lo que últimamente se da con frecuencia en el habla de los colombianos y venezolanos, mientras en otras variedades, en general, significa 'homosexual'. 
La variación dialectal de los vocativos en los países de habla hispana

Como es muy frecuente en Colombia y Venezuela, muy pocas personas de los encuestados procedentes de estos países piensan que este vocativo sea ofensivo. No se puede decir lo mismo de España y México donde este apelativo significa 'homosexual' y ofende a la gran mayoría, aunque algunos aceptan que en otras variedades es de frecuente uso sin ningún sentido ofensivo, así que ellos tampoco lo toman mal cuando lo escuchan.

\section{Conclusiones y futuras investigaciones}

Nuestra investigación pretendía ampliar nuestros conocimientos sobre los vocativos dialectales. Para la consecución de tal objetivo, primero presentamos las características principales de los vocativos a nivel fonológico, morfosintáctico, semántico y pragmático. La parte restante del trabajo es una investigación propia; elaboramos un corpus de 400 ejemplos (fragmentos, diálogos, frases, que en total contienen 493 vocativos), extraídos de telenovelas, películas, series, videos y páginas de Facebook y, basándonos en los vocativos encontrados, diseñamos una encuesta de 6 preguntas que servía para justificar o refutar nuestras hipótesis.

Nuestra primera hipótesis fue que existían vocativos pertenecientes a una sola variedad que no necesariamente eran reconocibles para los hablantes de otros países. Para ponerla a prueba, formulamos preguntas en torno a los siguientes vocativos: parcero, pelado, pana, chamo, carnal, güey, tío/ tía, gilipollas. Los resultados mostraron que sí existen vocativos dialectales que no siempre resultaron ser reconocidos por hablantes de otras variedades y su uso puede depender de la edad o del nivel intelectual del hablante. En general, son comunes entre amigos y gozan de menos frecuencia entre parejas o una relación asimétrica.

La segunda hipótesis fue que las mismas palabras en función de vocativo presentaban diferencias en cuanto a su significado, dependiendo de la variedad. Para justificarla, examinamos varios tipos de vocativos. De los resultados podemos llegar a la conclusión de que en Venezuela se apela a desconocidos también con vocativos que designan amistad.

Mamacita/mamita fuera de Colombia no designa cariño hacia las mujeres, pero si la entonación no es adecuada hasta en Colombia lo consideran ofensivo. Marico/marica en Venezuela y en Colombia se utiliza entre amigos, pero en México y en España sigue siendo ofensivo, aunque algunos aceptan que en otras variedades no tiene significado ofensivo, por lo que no se ofenden cuando lo escuchan. 
En conclusión, podemos constatar que las dos hipótesis fueron justificadas por nuestros resultados, es decir, hay vocativos específicos de una sola variedad que no necesariamente son reconocibles para hablantes de otras variedades, y también hay vocativos cuyo uso y significado se diferencia dependiendo de la variedad.

En una futura investigación sería interesante examinar los vocativos de los demás países latinos y también aumentar el número de los informantes de los cuatro países ya examinados. Nos interesaría comparar la frecuencia del uso de los vocativos cariñosos en el habla escrita y en el habla oral. También valdría la pena hacer un estudio sobre los nombres de animales que pueden funcionar tanto como adjetivos como como vocativos (lobo, zorro, perro), ya que su significado varía entre la forma masculina y femenina, y como hipótesis, podríamos suponer que las formas femeninas son más ofensivas. Y, por último, también nos gustaría escribir sobre los resultados de la pregunta sobre los vocativos ofensivos, ya que en este trabajo no ha sido posible su presentación. Nos gustaría ver cuán ofensivo consideraron los vocativos enumerados y si se puede detectar cierta diferencia dialectal en las respuestas.

\section{Fuentes utilizadas para el corpus:}

Colombia:

(COL-1) Las muñecas de la mafia (director: Luis Alberto Restrepo, 2009)

(COL-2) La reina del sur (director: Walter Doehner, 2011)

(COL-3) Sin senos si hay paraíso (director: Gustavo Bolívar, 2016)

(COL-4) Sin senos si hay paraíso 2 (director: Gustavo Bolívar, 2017)

(COL-5) La gente anda diciendo (Página de Facebook)

\section{España:}

(ESP-1) La reina del sur (director: Walter Doehner, 2011)

(ESP-2) Tres metros sobre el cielo (director: Fernando González Molina, 2010)

(ESP-3) Tengo ganas de ti (director: Fernando González Molina, 2012)

(ESP-4) Ocho apellidos vascos (director: Emilio Martínez-Lázaro, 2014)

(ESP-5) Rumbos (director: Manuela Burló Moreno, 2016)

(ESP-6) Qué harías si fueras Dios | Preguntas Botellón (canal de YouTube: Fortfast WTF, 2014)

(ESP-7) Machismo y la juventud (canal de You'Tube: Fortfast WTF, 2016)

México:

(MEX-1) Mujeres asesinas (director: Mafer Suárez, 2010)

(MEX-2) Perras (director: Guillermo Ríos, 2011)

(MEX-3) Nosotros los nobles (director: Gary Alazraki, 2013) 
La variación dialectal de los vocativos en los países de habla hispana

(MEX-4) El cumple de la abuela (director: Javier Colinas, 2016)

(MEX-5) La reina del sur (director: Walter Doehner, 2011)

(MEX-6) Por ella soy Eva (director: Benjamín Cann, 2012)

(MEX-7) Sin senos sí hay paraíso 2 (director: Gustavo Bolívar, 2017)

(MEX-8) Niñas rompe madres (canal de YouTube: JuStYosS, 2016)

(MEX-9) Dos estúpidas fresas - YosStop (canal de YouTube: YosStoP, 2014)

Venezuela:

(VZL-1) Juana, la virgen (director: Tony Rodríguez, 2002)

(VZL-2) La invasora (director: Otto Rodríguez, 2003)

(VZL-3) Rebeca (director: Yaki Ortega, 2003)

(VZL-4) Amor secreto (director: Carlos Izquierdo, 2015)

(VZL-5) Papita, mani, tostón (director: Luis Carlos Hueck, 2013)

\section{Referencias bibliográficas}

Alcina Franch, Juan - Blecua, José Manuel (1975). Gramática española. Barcelona: Ariel. Ávila, Raúl (2005). Españolismos y mexicanismos: un análisis cuantitativo. Nueva Revista de Filología Hispánica T. 53(2). 413-455.

Baditzné Pálvölgyi, Kata - Takács, Lili (2018). La traducción de los vocativos latinoamericanos al húngaro en obras literarias y películas. En: Bárkányi Zsuzsanna Santosné Blastik Margit (eds.): Palabras enlazadas. Estudios en homenaje al profesor László Scholz: Szeged: JATEPress, 2018. 23-34.

Baditzné Pálvölgyi, Kata (2015). A szóbeli kifejezőkészség fejlesztendő elemei a spanyolnyelv-órán. En: Éva Major - Etelka Tóth (eds.): Szakpedagógiai körkép II.: Idegennyelv-pedagógiai tanulmányok. Budapest: Eötvös Loránd Tudományegyetem. 131-151.

Bosque, Ignacio - Demonte, Violeta (2000). Gramática descriptiva de la lengua española. Real Academia Española. Madrid: Espasa.

Boyer, Julie (2013). Forma y función de los juegos fónicos en el habla juvenil de Puebla (México). Montreal: Université de Montréal.

Brown, Penelope - Levinson, Stephen (1987). Politeness. Some Universals in language Usage. Cambridge: University Press.

Bühler, Karl (1985). Teoría del lenguaje. Madrid: Alianza Universidad.

Bürki, Yvette (2014). Prácticas discursivas y estereotipos: la figura del naco en la sociedad mexicana actual. En: Kunz, Marco; Mondragón, Cristina; Phillipps-López, Dolores (eds.): Nuevas narrativas mexicanas II. Barcelona: Lingua. 400-427. 


\section{Lili Takács}

Carbonero, Pedro (2004). Destrezas sociolingüisticas y pragmáticas en las gramáticas y en los diccionarios. Sevilla: Universidad de Sevilla.

Carricaburo, Norma (2015). Las fórmulas de tratamiento en el español actual. Madrid: Arco/Libros.

Castañeda, Luz Stella - Henao, José Ignacio (2012). Fórmulas de apertura y cierre en procesos de interacción verbal en parlache. Departamento de Lingüística y Literatura. Universidad de Antioquia: Lingüística y Literatura. 62. 47-62.

Castellano Ascencio, Milton Daniel (2008). Fórmulas de tratamiento nominales para la pareja en el habla juvenil medellinense. En: Íkala, Revista de Lenguaje y Cultura, 13 (20). 163-181.

Castrillón, Sonia (2015). Sí, señor, soy colombiano de pura cepa, et toi? Las formas de tratamiento del español colombiano en Montreal. Université de Montréal: Département de Littératures et de Langues du Monde.

Cerrón-Palomino, Rodolfo (2016). El lenguaje como hermenéutica en la comprensión del pasado: A propósito del puquina en la génesis del Imperio Incaico. Diálogo Andino, 49. 11-27.

Corominas, Joan - Pascual, José Antonio (1980). Diccionario crítico etimológico castellano e bispánico Vol. II, Madrid: Editorial Gredos, S. A.

Corominas, Joan (1987). Breve diccionario etimológico de la lengua española. Madrid: Editorial Gredos, S.A.

D’Amore Wilkinson, Anna Maria (2013). La traducción de colores en Dos crímenes: entre racismo y alteridad. En: Castro Ramírez, N. (ed.). Traducción, identidad y nacionalismo en Latinoamérica. México: Bonilla Artigas Editores. 205-220.

Del Valle de Villalba, María Elena (2013). La enseñanza en la historia de Venezuela: algunas recomendaciones. Revista de Comunicación de la SEECI. (Marzo 2013). 132-148.

Domonkosi, Ágnes (2002). Megszólitások és beszédpartnerre utaló elemek a nyelvbasználatunkban. A Debreceni Egyetem Nyelvtudományi Intézetének Kiadványai.

Flores, Luis (1963). El español hablado en Colombia y su atlas lingüístico. Bogotá: Instituto Caro y Cuervo.

García Padrón, Dolores (2004). Significado y variación de la raíz part- en español. Revista Española de Lingüística, 3(2). 455-480.

García Rodríguez, Alba (2013). Análisis de los procedimientos apelativos en un serial colombiano de cuarta generación. Signo y seña. Asequible en:

http://revistascientificas.filo.uba.ar/index.php/sys/article/view/3213/2849, fecha de consulta: 23-09-2019.

García Zapata, Carlos (2014). Intensificadores disfemísticos en la literatura antioqueña. Lingüistica y literatura, 66. 39-64. Asequible en: 
La variación dialectal de los vocativos en los países de habla hispana

http://aprendeenlinea.udea.edu.co/revistas/index.php/lyl/article/view/20210/17100, fecha de consulta: 02-04-2018.

Gutiérrez-Rivas, Carolina (2016). La palabra marico como nueva forma de tratamiento nominal anticortés en el habla de jóvenes universitarios de Caracas: un estudio desde la perspectiva de los hablantes. Logos. Revista de Lingüistica, Filosofía y Literatura, 26(1). 3-22. Haensch, Günther (2002). Español de América y español de Europa (2.a parte). Panace@, 3(7).37-64.

Hasbún Hasbún, Leyla (2003). ¿Qué le vendemos, reina? El uso de los vocativos en la feria del agricultor. En: Filología y Lingüistica, XXIX (1). 201-212.

Jakobson, Roman (1968). Ensayos de lingüistica general. Madrid: Gredos.

Lara, Luis Fernando (1996). Diccionario del español usual en México. México: Colegio de México.

León, Victor (1984). Diccionario de argot español. Madrid: Alianza Editorial.

Lipski, John (2014). El español de América. Madrid: Cátedra.

Lo Ponte Pérez, Caterina (2016). Análisis de la variación del español en Venezuela a través de video y grabaciones. Asequible en:

http://tesi.cab.unipd.it/51653/1/CATERINA_LO_PONTE_PEREZ_2016.pdf, fecha de consulta: 23-09-2019.

Llorente Pinto, María del Rosario (2000). Cuestiones de actualidad en lengua española. Salamanca: Universidad de Salamanca. 235-244.

Manzini, Margherita (2017). Spanglish: dos idiomas, dos culturas y dos civilizaciones. Análisis de «The Raza who Scored big in Anahuac»y «El Bacalao viene de más lejos y se come aquí». Glosas, 9(3). 25-43.

Moberg, Emma (2015). El uso de huevón y sus derivados en el habla coloquial de Santiago de Chile: Un estudio sociolingüistico. (Disertación). Asequible en:

http://www.diva-portal.org/smash/get/diva2:838756/FULLTEXT01.pdf, fecha de consulta: 31-09-2019.

Mugford Fowler, Gerrard., Lomelí, Sergio y Vázquez Robles, Estefanía (2013). La comunión fática como práctica local: la anticortesía y la cortesía positiva en el contexto mexicano / Phatic communion as local practice: anti-politeness and positive politeness in the Mexican context. Pragmática Sociocultural / Sociocultural Pragmatics, 1(2). 199-226.

Parodi, Claudia (2003). De la sincronía a la diacronía: Contacto de dialectos. En: América. Estudios de lingüistica y filología hispánicas en honor de José G. Moreno de Alba. En Memoria del IV Encuentro de lingüística en Acatlán. México: UNAM, 125-146.

Portocarrero, Cosme (1999). La palabra huevón. Santiago de Chile: LOM Ediciones.

Queiroz, Amarino Oliveira de (2016). Alteridades artísticas e culturais afroamericanas: Nicolás Guillén, Solano Trindade, e Nicomedes Santa Cruz. Entheoria: Cuadernos de Letras e Humanas, 3(1). 79-93. 
RAE (1999). Esbozo de una nueva gramática de la lengua española. Madrid: Espasa Calpe.

Richard, Renaud (2006). Diccionario de Hispanoamericanismos no recogidos por la Real Academia. Madrid: Cátedra.

Rojas, Darío (2012). Huevón como marcador del discurso en el español de Chile: huellas de un proceso de gramaticalización. Revista de Humanidades, 25. 145-164.

Sáez-Godoy, Leopoldo (1983). Una familia léxica del español común e informal de Chile: hueva y sus derivados. En: Estudios lingüisticos en memoria de Gastón Carrillo Herrera. Bonn: Rheinische Friedrich-Wilhelms-Universität Bonn. 133-149.

Scholz, László - Zavaleta, Julio (eds.) (1997). Introducción a la lingüistica. Crestomatía de textos en español. Budapest: Eötvös József Könyvkiadó.

Seco, Manuel (1989). Gramática esencial del español. Introducción al estudio de la lengua. Madrid: Espasa Calpe.

\section{Páginas web:}

http://rumbacaracas.com/noticias/2015/01/23/de-donde-provienen-la-palabraschamo-y-pana/(última consulta: 10-10-2018).

Diccionario Clave: http://clave.smdiccionarios.com/app.php (última consulta 23-09-2019).

Diccionario Glosbe: https://es.glosbe.com/ (última consulta 23-09-2019). 